\title{
The characteristics of dyslipidemia patients with different durations in Beijing: a cross-sectional study
}

Yingying Liu ${ }^{1,2 \dagger}$, Puhong Zhang ${ }^{3 \dagger}$, Wei Wang ${ }^{1}$, Huan Wang ${ }^{1}$, Ling Zhang ${ }^{1}$, Wei Wu' ${ }^{1}$ Xiuhua Guo ${ }^{1 *}$

\begin{abstract}
Background: Prevalence of dyslipidemia is high and increases even in younger people. The key aim of this study was to explore the group characteristics of patients in different durations of dyslipidemia and provide clues for the management of dyslipidemia in Beijing.

Results: Patients with short duration of dyslipidemia were mainly characterized by relatively young age, occupational groups, not eating or irregular eating breakfast, less physical activities, having the habit of smoking, and $53.8 \%$ is with abnormal LDL-C, $10.4 \%$ is with abnormal HDL-C, and $51.5 \%$ is with abnormal TG. $54.6 \%$ of patients with longer duration is with abnormal LDL-C, $12.8 \%$ of them is with abnormal HDL-C, and $57.1 \%$ is with abnormal TG. They paid much more attentions to their health, tried to eat breakfast regularly and do more physical activities, gave up smoking, and had regular breakfast, but increasing physiological disorders such as elevated blood pressure and glucose appeared. Severe sequelaes (stroke, myocardial infarction) were mainly observed in patients with the duration of more than 10 years. And in this group the proportions of patients with $\mathrm{LDL}-\mathrm{C} \geq 4.15 \mathrm{mmol} / \mathrm{L}$ and $\mathrm{TG} \geq 4.53 \mathrm{mmol} / \mathrm{L}$ are the highest among the three groups.

Conclusions: we should strengthen the tertiary prevention and improve the control rate of dyslipidemia in Beijing. Health promotion programs such as tobacco control and physical exercise should be carried out for younger patients.
\end{abstract}

\section{Background}

Dyslipidemia, a common lipid abnormality is characterized by elevated lowdensity lipoprotein cholesterol (LDL-c), elevated triglycerides (TGs), or low high density lipoprotein cholesterol (HDL-c) [1]. Prevalence of dyslipidemia is high and becomes to increase even in younger people [2]. In addition to elevated LDL-c, both low HDL-c and elevated TG are increasingly being recognized as independent risk factors for coronary heart disease (CHD) $[3,4]$. Dyslipidemia is one of the leading causes of death and cardiovascular morbidity in western countries [5]. Hypertension, dyslipidemia, endothelial dysfunction and oxidative stress are the major pathologies involved in CVDs and

\footnotetext{
* Correspondence: guoxiuh@ccmu.edu.cn

† Contributed equally

'Department of Epidemiology and Health Statistics, School of Public Health and Family Medicine, Capital Medical University, No.10 Xitoutiao, You An Men Wai, Beijing, China

Full list of author information is available at the end of the article
}

impose a great risk [6]. Dyslipidemia is responsible for $54 \%$ of population attributable risk for myocardial infarction (MI) $[7,8]$. Dyslipidemia is also an important contributor to cardiovascular risk in people with metabolic syndrome [6]. Dyslipidemia is consanguineously related with life style [9]. Better high-density lipoprotein (HDL) can be gotten through changing the lifestyle [10]. And hypercholesterolaemia is the permissive factor that allows other risk factors to operate [11]. If the TC decreased 1\%, the incidence of CHD will reduce $2 \%$. And if TC decreased $10 \%$, the mortality of CHD will reduce $13 \% \sim 14 \%$ [12].

The importance of dyslipidemia management is based on cardiovascular risk factors. Assessment of the patient's risk for coronary heart disease helps determine which treatment should be initiated [13]. The lipid management goal is also based on risk assessment and the management of dyslipidemia doesn't always require drug therapy. Particularly, lifestyle modification is important for the management of low HDL-C and TG [14]. We manage to
C Biomed Central

() 2010 Liu et al; licensee BioMed Central Ltd. This is an Open Access article distributed under the terms of the Creative Commons Attribution License (http://creativecommons.org/licenses/by/2.0), which permits unrestricted use, distribution, and reproduction in any medium, provided the original work is properly cited. 
explore the group characteristics of patients in different durations of dyslipidemia through a cross-sectional investigation which will assess cardiovascular risk factors of the dyslipidemia patients and provide clues for the prevention and therapy of dyslipidemia in Beijing.

\section{Methods}

\section{Survey methodology}

A cross-sectional study was performed to research the prevalence level of chronic diseases and risk factors in Beijing in 2005, in which, the target people involved was aged $\geq 18$ years old and had been living in Beijing for at least 6 months. In the study, 19216 individuals who represented 19216 families involved in the survey with multi-stage cluster sampling study, and this investigation covered 162 communities of 54 sub districts in all 18 municipal districts. The sub districts were sampled with probability proportional to size cluster sampling method in each district. 16711(87.0\%) subjects were valid and used in consequent studies. And 2692 diagnosed dyslipidemia patients with complete duration information from the 16711 valid participants were chosen for the correspondence analysis in this study.

Our survey included a questionnaire, physical measurements, blood pressure measurements and laboratory tests to collect information. Before the investigation all the people involved had signed the informed consents. We used Calender 7600 autoanalyzer to test fasting lipid components for the diagnosis of dyslipidemia in the laboratory of Beijing CDC(the Center for Disease Control and Prevention).

\section{Diagnosis methods and a layered approach}

Dyslipidemia was diagnosed as any abnormal status of LDL-C, HDL-C and TG (based on the standard of ATPIII: $\mathrm{TG} \geq 1.70 \mathrm{mmol} / \mathrm{L}, \mathrm{LDL}-\mathrm{c} \geq 3.46 \mathrm{mmol} / \mathrm{L}, \mathrm{HDL}-\mathrm{c}<0.91$ $\mathrm{mmol} / \mathrm{L}$ ), And basing on the standard of ATPIII, TG was divided into four groups(TG $<1.70 \mathrm{mmol} / \mathrm{L}, 1.70 \leq \mathrm{TG}$ $<2.27 \mathrm{mmol} / \mathrm{L}, 2.27 \leq \mathrm{TG}<4.52 \mathrm{mmol} / \mathrm{L}, \mathrm{TG} \geq 4.53$ $\mathrm{mmol} / \mathrm{L}$ ); LDL-c was divided into three groups(LDL-c $<3.46 \mathrm{mmol} / \mathrm{L}, 3.46 \leq \mathrm{LDL}-\mathrm{c}<4.15 \mathrm{mmol} / \mathrm{L}$, LDL-c $\geq 4.15 \mathrm{mmol} / \mathrm{L}$ ); HDL-c was divided into three groups (HDL-c $<0.91 \mathrm{mmol} / \mathrm{L}, 0.91 \leq \mathrm{HDL}-\mathrm{c}<1.56 \mathrm{mmol} / \mathrm{L}$, HDL-c $\geq 1.56 \mathrm{mmol} / \mathrm{L}$ ). The duration of dyslipidemia was calculated according to the date on which one was first diagnosed as dyslipidemia patient. Body mass index (BMI) was calculated as body weight divided by height squared $\left(\mathrm{kg} / \mathrm{m}^{2}\right)$. Lower-weight $(\mathrm{L}-\mathrm{W})$, normal-weight $(\mathrm{N}-\mathrm{W})$, overweight and obesity were defined as $\mathrm{BMI}<18.5,18.5 \leq$ $\mathrm{BMI}<25,25 \leq \mathrm{BMI}<30$ and $\mathrm{BMI} \geq 30$, respectively.

Current smokers included regular and casual smokers within the last month and were classified as nonsmoking, 0-9 cigarettes/day, 10-19 cigarettes/day, 20-29 cigarettes/day and $\geq 30$ cigarettes/day. Drinking groups included non-drinking (never drink or drink less than 1 time per month), occasional drinking (drink more than 1 time per month but less than 2 times per week) and frequent drinking (drink more than 2 times per week). Lack of physical activities referred to less than 2 hour physical activities per week including walking, dancing, running, swimming and court game, excluding work purpose physical activities. Low-intake of calcium, low-intake of fruit and vegetable and protein intake were all based on food frequency questionnaire.

According to the measurement of blood pressure(BP), we defined the normal BP, borderline hypertension, lowgrade hypertension, middle-grade hypertension and highgrade hypertension as SBP $<130 \mathrm{mmHg}$ and $\mathrm{DBP}<85$ $\mathrm{mmHg}, 130 \mathrm{mmHg} \leq \mathrm{SBP}<140 \mathrm{mmHg}$ or $85 \mathrm{mmHg}$ $\leq \mathrm{DBP}<90 \mathrm{mmHg}, 140 \mathrm{mmHg} \leq \mathrm{SBP}<160 \mathrm{mmHg}$ or $90 \mathrm{mmHg} \leq \mathrm{DBP}<100 \mathrm{mmHg}, 160 \mathrm{mmHg} \leq \mathrm{SBP}<180$ $\mathrm{mmHg}$ or $100 \mathrm{mmHg} \leq \mathrm{DBP}<110 \mathrm{mmHg}, \mathrm{SBP} \geq 180$ $\mathrm{mmHg}$ or DBP $\geq 110 \mathrm{mmHg}$. And according to the fasting plasma glucose (FPG), normal FPG, impaired fasting glucose(IFG) and diabetes were defined as FPG $<6.1$ $\mathrm{mmol} / \mathrm{L}, 6.1 \mathrm{mmol} / \mathrm{L} \leq \mathrm{FPG}<7.0 \mathrm{mmol} / \mathrm{L}$ and $\mathrm{FPG} \geq 7.0$ $\mathrm{mmol} / \mathrm{L}$. We diagnosed metabolic syndrome (MS) as the standard of ATPIII. The consideration of myocardial infraction and stroke were according to the diagnosis of local hospitals.

The sample size of each duration group was: "0-4 years": 1816 (67.5\%); “5-9 years": 517 (19.2\%); “ $\geq 10$ years”:359 (13.3\%).

\section{Statistical analysis}

All data were doubly input and checked with Epidata3.1 by a professional data recording company. Abnormal values and missing values were checked (logic check) by quality control group to ensure the data accuracy. SAS software (version 9.1, SAS Institute (Shanghai) Co., Ltd.) was used to perform univariate analysis and multiple correspondence analysis. Prior to multiple correspondence analysis, univariate analysis were made to find significant variables. Nonparametric test was used to explore the correlation between a particular correlated factors and durations of dyslipidemia. We performed Mann-Whitney with the variables classified as two levels, and Kruskal-Wallis for variables classified as multilevel out of orders (such as occupation), and Spearman rank correlation analysis for variables classified as multilevel orders.

Correspondence analysis is used to analyze the differences among every sort of one same variable and the corresponding relationship among every sort of variable. This method is converting an original data matrix $\mathrm{X}=$ (x) nm contains $n$ subjects and $m$ variables into another matrix $\mathrm{Z}=(\mathrm{z}) \mathrm{nm}$, and also making $\mathrm{R}=\mathrm{Z} \mathrm{Z}$ (covariance matrix analyzing the relationship among variables) and 
$\mathrm{Q}=\mathrm{ZZ}$ (covariance matrix analyzing the relationship among subjects) have the same non-zero eigenvalue by utilizing a sort of data transformation method. The horizontal axis of the correspondence analysis graph is the first dimensionality, and the second dimensionality is the vertical axis. The distance between the two variables can indicate the approximate relationship between the two variables $[15,16]$.

\section{Results}

The awareness and control rates of dyslipidemia are low in Beijing

According to the new test results of TC, TG, LDL, HDL, there are 6709 dyslipidemia patients among 16711 subjects. And the prevalence rate of dyslipidemia is $40.15 \%$. And according to the questionnaire, the awareness, control rates of dyslipidemia were $43.79 \%$ and $17.20 \%$ respectively. $17.35 \%$ of the patients control dyslipidemia through taking drugs, $3.61 \%$ of the patients through dietary restriction and $10.51 \%$ through physical exercises. Among 6709 dyslipidemia patients, 2692 cases can recall when and where their dyslipidermia were diagnosed while 249 patients can't. And 3768 patients are newly diagnosed through our investigation. Among the 2692 patients with complete duration information, $7.0 \%(188)$ was diagnosed in Community Health Station, $13.2 \%(354)$ was diagnosed in Health service centers in Communities, $48.0 \%(1293)$ was diagnosed in Chinese Level II Hospital, and 31.8\%(853) was diagnosed in Tertiary Health Care. And the lipid degrees and BMI of dyslipidemia patients with different durations is shown in table 1.

The LDL-c, HDL-c and TG levels of patients with the $0-4$ years duration are $3.53 \pm 0.96 \mathrm{mmol} / \mathrm{L}, 1.25 \pm 0.32$ $\mathrm{mmol} / \mathrm{L}, 2.17 \pm 1.72 \mathrm{mmol} / \mathrm{L}$. The LDL-c, HDL-c and
TG levels of patients with the 5-9 years duration are $3.56 \pm 0.98 \mathrm{mmol} / \mathrm{L}, 1.23 \pm 0.31 \mathrm{mmol} / \mathrm{L}, 2.37 \pm 1.79$ $\mathrm{mmol} / \mathrm{L}$. The LDL-c, HDL-c and TG levels of patients with the $\geq 10$ years duration are $3.56 \pm 0.961 .19 \mathrm{mmol} /$ L, $1.26 \pm 0.36 \mathrm{mmol} / \mathrm{L}, 2.38 \pm 1.89 \mathrm{mmol} / \mathrm{L} .53 .8 \%$ of patients in 0-4 years duration is with abnormal LDL-c, $10.4 \%$ is with abnormal HDL-c, and $51.5 \%$ is with abnormal TG, while $47.2 \%$ is overweight and $27.3 \%$ is obesity; $54.6 \%$ of patients in $5-9$ years duration is with abnormal LDL-c, $12.8 \%$ is with abnormal HDL-c, and $57.1 \%$ is with abnormal TG, while $46.8 \%$ is overweight and $30.2 \%$ is obesity; $56.9 \%$ of patients in 10 years or more duration is with abnormal LDL-c, $12.6 \%$ is with abnormal HDL-c, and $53.6 \%$ is with abnormal TG, while $43.3 \%$ is overweight and $33.2 \%$ is obesity. The proportion of patients with LDL-c $\geq 4.15 \mathrm{mmol} / \mathrm{L}$ is increasing with the increasing duration among the three groups while the proportion of patients with $3.46 \mathrm{mmol} / \mathrm{L}$ $\leq \mathrm{LDL}-\mathrm{c}<4.15 \mathrm{mmol} / \mathrm{L}$ is decreasing. The proportion of obese people is increasing with the increasing duration among the three groups.

\section{Distribution of correlated factors and diseases in patients with different durations of dyslipidemia}

Nineteen major factors were enrolled in the initial univariate analysis. These factors were living area, gender, educational degree, age group, occupation, current smoking status, status of breakfast, alcohol intake, status of physical activities, oil intake, degree of salt intake, low-intake of calcium, low-intake of vegetable, inefficient protein intake, degree of total cholesterol, degree of HDL-C, degree of TG, degree of LDL-C, BMI. In the same way, the correlated diseases (hypertension, diabetes, myocardial infraction, stroke, metabolic syndrome and centripetal obesity) of dyslipidemia were chosen to

Table 1 the lipid level and BMI of dyslipidemia patients with different durations

\begin{tabular}{|c|c|c|c|c|c|c|c|c|c|}
\hline & & \multicolumn{2}{|c|}{$0 \sim 4$ years } & \multicolumn{2}{|c|}{$5 \sim 9$ years } & \multicolumn{2}{|c|}{10 years } & \multirow[t]{2}{*}{ Statistic } & \multirow[t]{2}{*}{$P$ value } \\
\hline & & $\mathrm{n}$ & $\%$ & $n$ & $\%$ & $n$ & $\%$ & & \\
\hline \multirow[t]{3}{*}{ LDL-c (mmol/L) } & $<3.46$ & 839 & 46.2 & 235 & 45.4 & 154 & 43.1 & & \\
\hline & $3.46 \sim$ & 544 & 30.0 & 141 & 27.3 & 95 & 26.5 & & \\
\hline & $\geq 4.15$ & 433 & 23.8 & 141 & 27.3 & 109 & 30.4 & 0.037 & 0.057 \\
\hline \multirow[t]{3}{*}{$\mathrm{HDL}-\mathrm{c}(\mathrm{mmol} / \mathrm{L})$} & $<0.91$ & 189 & 10.4 & 66 & 12.8 & 45 & 12.6 & & \\
\hline & $0.91 \sim$ & 1365 & 75.2 & 378 & 73.1 & 260 & 72.6 & & \\
\hline & $1.56 \sim$ & 262 & 14.4 & 73 & 14.1 & 53 & 14.8 & -0.020 & 0.308 \\
\hline \multirow[t]{4}{*}{$\mathrm{TG}(\mathrm{mmol} / \mathrm{L})$} & $<1.70$ & 881 & 48.5 & 222 & 42.9 & 166 & 46.4 & & \\
\hline & $1.70 \sim$ & 352 & 19.4 & 105 & 20.3 & 63 & 17.6 & & \\
\hline & $2.27 \sim$ & 457 & 25.2 & 144 & 27.9 & 94 & 26.3 & & \\
\hline & $\geq 4.53$ & 126 & 6.9 & 46 & 8.9 & 35 & 9.8 & 0.045 & 0.020 \\
\hline \multirow[t]{4}{*}{ BMl } & L-W & 12 & 0.7 & 1 & 0.2 & 1 & 0.3 & & \\
\hline & $\mathrm{N}-\mathrm{W}$ & 449 & 24.7 & 118 & 22.8 & 83 & 23.2 & & \\
\hline & overweight & 859 & 47.3 & 242 & 46.8 & 155 & 43.3 & & \\
\hline & obesity & 496 & 27.3 & 156 & 30.2 & 119 & 33.2 & 0.043 & 0.026 \\
\hline
\end{tabular}


perform univariate analysis in order to observe the assembling mode. The significant statistic results were shown in Table 2 and Table 3.

\section{Multiple correspondence analysis on the durations of dyslipidemia and correlated factors}

We excluded the insignificant factors in univariate analysis, and carried out multiple correspondence analysis on durations of dyslipidemia. Multiple correspondence analysis graph was shown in Fig 1. From the distance between codes which present the three durations of dyslipidemia and their risk factors at different level shown in Fig 1, we found that patients with duration of dyslipidemia less than 5 years were correlated with the identities of living in rural area, young to middle aged, worker, civil servant or farmer, not eating or irregular eating breakfast, less physical exercise, occasionally or often smoking; Patients with duration of 5-9 years were mainly assembled with living in urban area, 50-59 years old, eating breakfast every day, no smoking or heavy smoking, doing more physical exercises; And patients with duration of dyslipidemia $\geq 10$ years concentrated mainly on retired or unemployed citizens, aged above 60 years old.

We selected the significant statistic factors listed in table 2 to perform multiple correspondence analysis.
Multiple correspondence analysis graph was shown in Fig 2. From the distance between the durations of dyslipidemia and their risk factors at different level according to Fig 2, we can find that patients with the duration less then 5 years was mainly assembled with normal in metabolism, blood glucose and blood pressure, without myocardial infarction stroke or centripetal obesity. Patients with the duration of dyslipidemia between 5-9 years gradually depart from normal status with critical hypertension, impaired fasting glucose(IFG), and get close to metabolic syndrome. And patients with duration more than 10 years were much closed with hypertension, diabetes mellitus(DM), myocardial infarction and stroke.

\section{Discussion}

As an extension to principal component analysis, correspondence analysis is a kind of descriptive multi-variable analysis method, factor analysis and canonical correlation analysis. Through projection from vector point of high dimensional space to lower dimensional space, multiple correspondence analysis can be used to clearly illustrate correlations among multiple variables in one simple two dimension chart through projection from vector point of high dimensional space to lower dimensional space, therefore, can generate some benefits like

Table 2 Distribution of correlated factors in patients with different durations of dyslipidemia

\begin{tabular}{|c|c|c|c|c|c|c|c|c|c|c|}
\hline & \multirow[t]{2}{*}{ code } & & \multicolumn{2}{|c|}{ 0 4 years } & \multicolumn{2}{|c|}{ 5 9 years } & \multicolumn{2}{|c|}{10 years } & \multirow[t]{2}{*}{ Statistic } & \multirow[t]{2}{*}{$P$ value } \\
\hline & & & $n$ & $\%$ & $n$ & $\%$ & $n$ & $\%$ & & \\
\hline \multirow[t]{5}{*}{ career } & CARE1 & worker & 188 & 76.1 & 34 & 13.8 & 25 & 10.1 & & \\
\hline & CARE2 & civil servant & 834 & 69.7 & 252 & 21.1 & 111 & 9.3 & & \\
\hline & CARE3 & resident & 464 & 57.0 & 174 & 21.4 & 176 & 21.6 & & \\
\hline & CARE4 & farmer & 157 & 74.0 & 33 & 15.6 & 22 & 10.4 & & \\
\hline & CARE5 & civil servant & 173 & 78.2 & 24 & 10.9 & 24 & 10.9 & 77.07 & $<0.001$ \\
\hline \multirow[t]{5}{*}{ age } & AGE1 & $18 \sim$ & 291 & 84.6 & 41 & 11.9 & 12 & 3.5 & & \\
\hline & AGE2 & $40 \sim$ & 629 & 74.7 & 150 & 17.8 & 63 & 7.5 & & \\
\hline & AGE3 & $50 \sim$ & 597 & 63.7 & 203 & 21.7 & 137 & 14.6 & & \\
\hline & AGE4 & $60 \sim$ & 209 & 55.8 & 83 & 22.1 & 83 & 22.1 & & \\
\hline & AGE5 & $70 \sim$ & 90 & 46.7 & 40 & 20.7 & 63 & 32.6 & 0.24 & $<0.001$ \\
\hline \multirow[t]{2}{*}{ site } & SUB & Urban & 1183 & 65.0 & 362 & 19.9 & 275 & 15.1 & & \\
\hline & CITY & Rural & 633 & 72.7 & 155 & 17.8 & 83 & 9.5 & -4.31 & $<0.001$ \\
\hline \multirow[t]{5}{*}{ smoking group } & SMKO & none & 1305 & 69.5 & 342 & 18.2 & 230 & 12.3 & & \\
\hline & SMK1 & $1 \sim / d$ & 134 & 62.6 & 45 & 21.0 & 35 & 16.4 & & \\
\hline & SMK2 & $10 \sim / d$ & 160 & 66.4 & 47 & 19.5 & 34 & 14.1 & & \\
\hline & SMK3 & $20 \sim / d$ & 159 & 61.4 & 64. & 24.7 & 36 & 13.9 & & \\
\hline & SMK4 & $30 \sim / d$ & 57 & 58.2 & 19 & 19.4 & 22 & 22.4 & 0.07 & $<0.001$ \\
\hline \multirow[t]{2}{*}{ Exercise } & LACK-S & Lack & 1191 & 65.7 & 357 & 19.7 & 265 & 14.6 & & \\
\hline & $\mathrm{ACT}$ & enough & 621 & 71.4 & 156 & 18.0 & 92 & 10.6 & -3.21 & 0.001 \\
\hline \multirow[t]{4}{*}{ brfst } & BRFST1 & none & 116 & 73.0 & 29 & 18.2 & 14 & 8.8 & & \\
\hline & BRFST2 & $1-3 \mathrm{t} / \mathrm{w}$ & 109 & 73.6 & 25 & 16.9 & 14 & 9.5 & & \\
\hline & BRFST3 & $4-6 \mathrm{t} / \mathrm{w}$ & 129 & 75.0 & 31 & 18.0 & 12 & 7.0 & & \\
\hline & BRFST4 & everyday & 1462 & 66.1 & 432 & 19.5 & 318 & 14.4 & 0.69 & $<0.001$ \\
\hline
\end{tabular}


Table 3 Distribution of the correlated diseases in patients with different duration of dyslipidemia

\begin{tabular}{|c|c|c|c|c|c|c|c|c|c|c|}
\hline & \multirow[t]{2}{*}{ code } & & \multicolumn{2}{|c|}{$0 \sim 4$ years } & \multicolumn{2}{|c|}{ 5 9 years } & \multicolumn{2}{|c|}{10 years } & \multirow[t]{2}{*}{ Statistic } & \multirow[t]{2}{*}{$P$ value } \\
\hline & & & $n$ & $\%$ & $n$ & $\%$ & $n$ & $\%$ & & \\
\hline \multirow[t]{5}{*}{$\overline{\mathrm{HP}}$} & HPO & normal & 400 & 78.3 & 73 & 14.3 & 38 & 7.4 & & \\
\hline & HP1 & borderline & 648 & 66.9 & 199 & 20.5 & 122 & 12.6 & & \\
\hline & HP2 & low-grade & 492 & 65.3 & 152 & 20.2 & 109 & 14.5 & & \\
\hline & HP3 & middle-grade & 197 & 60.2 & 66 & 20.2 & 64 & 19.6 & & \\
\hline & HP4 & high-grade & 69 & 57.5 & 26 & 21.7 & 25 & 20.8 & 0.12 & $<0.001$ \\
\hline \multirow[t]{3}{*}{ DM } & DMO & normal & 1341 & 70.1 & 350 & 18.3 & 223 & 11.7 & & \\
\hline & IFG & IFP & 171 & 67.6 & 49 & 19.4 & 33 & 13.0 & & \\
\hline & $\mathrm{DM}$ & $\mathrm{DM}$ & 289 & 57.4 & 114 & 22.7 & 100 & 19.9 & 0.10 & $<0.001$ \\
\hline \multirow[t]{2}{*}{ MS } & MSO & not happened & 1164 & 70.3 & 294 & 17.8 & 197 & 11.9 & & \\
\hline & MS1 & happened & 628 & 62.5 & 219 & 21.8 & 158 & 15.7 & -4.21 & $<0.001$ \\
\hline \multirow[t]{2}{*}{ AMI } & AMIO & not happened & 1735 & 68.5 & 481 & 19.0 & 315 & 12.5 & & \\
\hline & AMI1 & happened & 32 & 38.1 & 20 & 23.8 & 32 & 38.1 & -6.57 & $<0.001$ \\
\hline \multirow[t]{2}{*}{ STROKE } & STRO & not happened & 1699 & 68.6 & 475 & 19.2 & 304 & 12.2 & & \\
\hline & STR1 & happened & 75 & 50.0 & 28 & 18.7 & 47 & 31.3 & -5.55 & $<0.001$ \\
\hline
\end{tabular}

that intuition, convenience, strong discriminating ability and saving calculating time, etc $[15,16]$. In our study the multiple variables assemble obviously.

The INTERHEART study also showed that nine traditional risk factors (smoking, hypertension, diabetes, obesity, diet, physical activity, alcohol consumption, psychosocial factors, and dyslipidemia) contributed to the high CHD burden in the South Asian population as in other countries. From the review of the report 'the nutrition and health status of Chinese' which was published by medical ministry of People's Republic of China in Oct, 2004, we knew that the prevalence of chronic

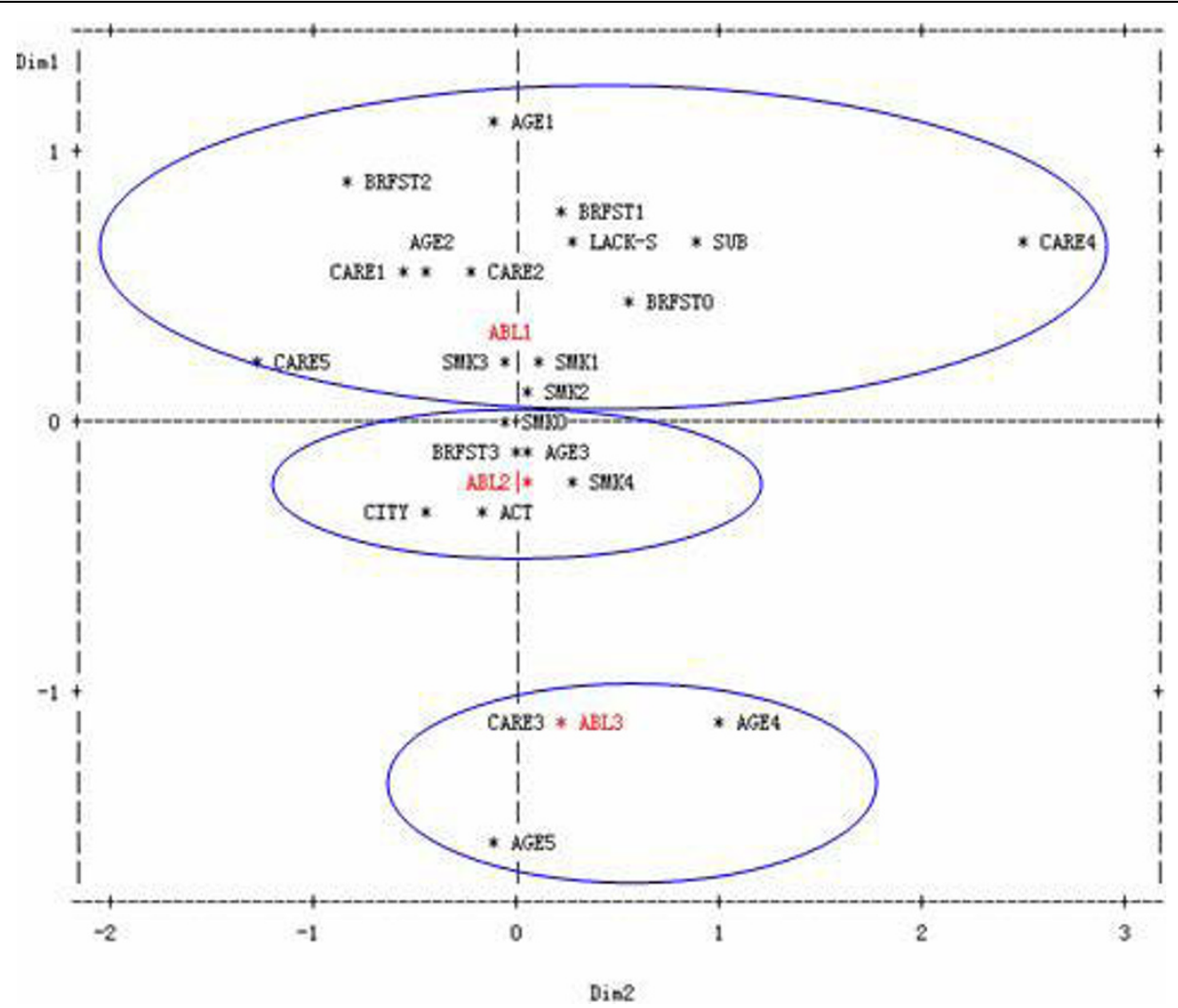

Figure 1 Multiple correspondence analyses of the duration of dyslipidemia and its correlated factors. The relevant abbreviations existed in Figure 1 are according to the codes presented in Table 2. 


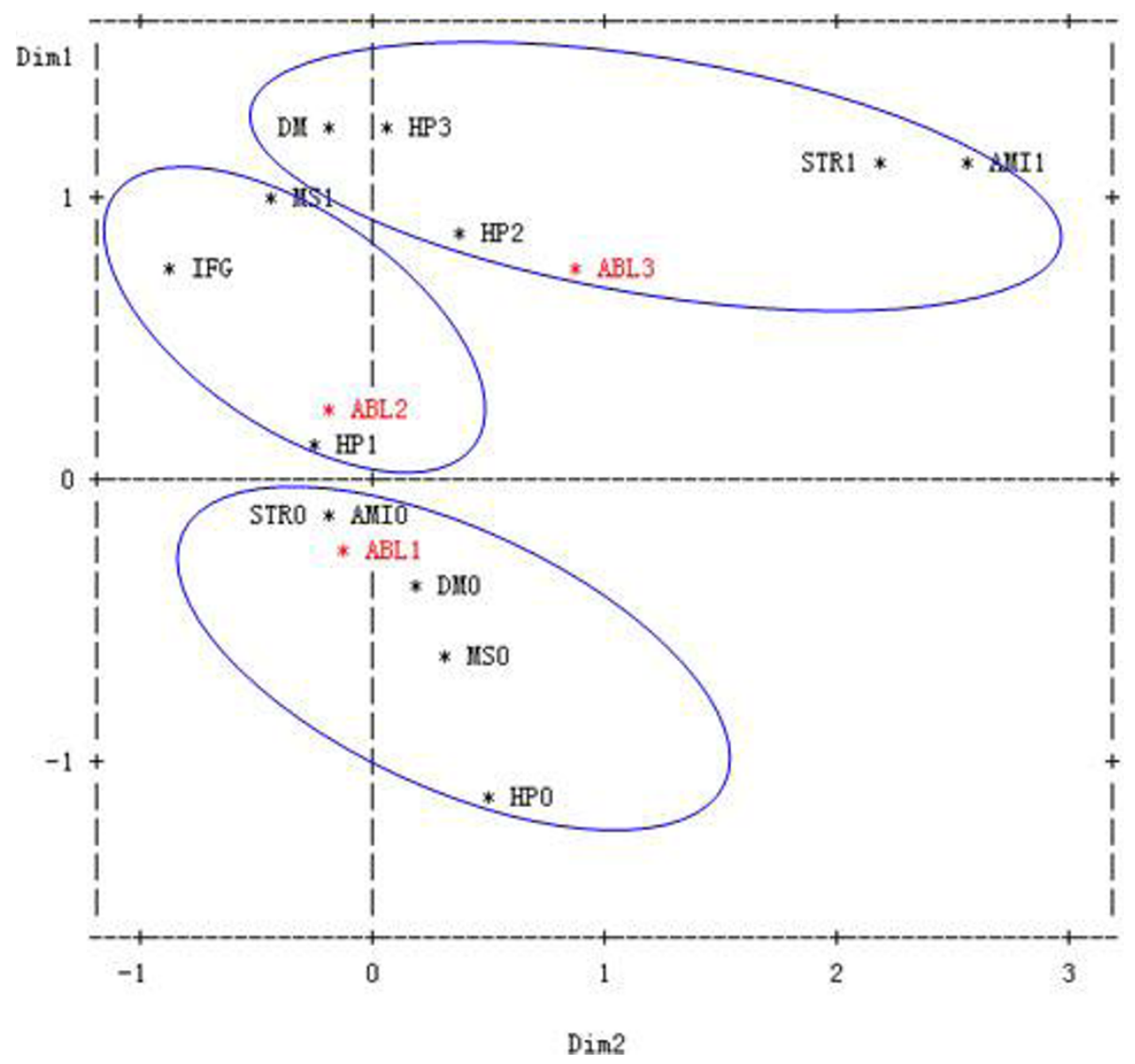

Figure 2 Multiple correspondence analyses of the duration of dyslipidemia and its correlated diseases. The relevant abbreviations existed in Figure 2 are according to the codes presented in Table 3.

disease such as hypertension, diabetes and dyslipidemia ascended rapidly and the unhealthy lifestyle was the main risk factor. Many researches had mentioned that direct or indirect smoking was one of the most important risk factors of dyslipidemia [17-19]. And the same Lack of physical activities and the habit of sedentariness were another risk factor of dyslipidemia [20]. And study suggested high prevalence of dyslipidemia in all age groups both in males and females and the prevalences were increasing with age [21]. In our study we also found that patients with shorter duration were closely related with lack of physical activities and having the habit of smoking. But the elder patients began to pay more attention to their health. And they tried to change their unhealthy lifestyle such as eating breakfast regularly, giving up smoking and doing more physical exercises, but metabolic syndrome had taken place in this period and critical hypertension and IFG happened during this period.

Tenkanen L' data showed that patients with dyslipidemia and features associated with the metabolic syndrome (BMI and TG in the highest tertiles) [22]. Hypertension, diabetes, and dyslipidemia are all factors individually associated with increased risk for mortality from cardiovascular disease and all-cause mortality [23]. Some type of diet was tested in clinical trials in Italy and shown to lower blood pressure and improve dyslipidemia [24]. Forsythe's study had suggested that a healthier diet favorably and strongly affects dyslipidemia and hypertension, even in obese patients who do not lose weight [20]. It has been indicated the combination of aerobic and resistance exercise may provide greater benefit in people with dyslipidemia and other components of the metabolic syndrome because of the combined effects of reduced adiposity, increased muscle mass, and improved myocyte function, including increased oxidative capacity [25]. According to the characteristics of patients with different duration of dyslipidemia in Beijing, We found the clues for the strategies about the prevention of dyslipidemia. At the earlier of dyslipidemia, patients were relatively young, lack of healthy sense, with the unhealthy life-style. With the development of dyslipidemia patients gradually suffered from other chronic diseases and they began to pay more attention to their health and change their unhealthy 
life-style. But with the effects of multiple causes myocardial infarction and stroke were inevitable. According to those characters, the strategies about the prevention of should be developed with changing young people's risk behavior. Because of the clustering of dyslipidemia, diabetes, hypertension and obesity, a comprehensive strategy should be made to improve the prevention of cardiovascular disease.

Because many different risk factors affect dyslipidemia patients with different duration, potentially complementary mechanisms of action, combination control may offer additional beneficial effects to patients with different duration of dyslipidemia. This study demonstrates that different duration of dyslipidemia with different risk factors which can effectively improve multiple intervention measures to a greater extent in patients with dyslipidemia, without significantly increasing the risk for adverse events commonly associated with unified intervention model. These findings in our paper have important public health implications for the prevention and treatments of dyslipidemia.

\section{Conclusions}

According to our research, we should strengthen the tertiary prevention and improve the control rate of dyslipidemia in Beijing. Community physicians should take effective measures to control blood lipids for patients with dyslipidemia. We should strengthen the prevention and treatment of dyslipidemia for younger people, Particularly for the working groups and community retired residents. Health promotion programs such as tobacco control and physical exercise should be carried out for younger patients. Community hospitals should establish files with chronic diseases patients. The blood lipids, blood glucose, blood pressure should strictly controlled for the dyslipidemia patients with the duration of more than five years and then we can prevent the serious complications such as myocardial infarction and stroke.

\footnotetext{
Acknowledgements

This project was funded by Beijing Health Bureau; The program of Natural Science Fund of China (Serial Number: 30972550); the program of Natural Science Fund of Beijing (Serial Number: 7092010); Program of Funds: The program of Natural Science Fund of China (Serial Number: 30972550); the program of Natural Science Fund of Beijing (Serial Number: 7092010); the program of Academic Human Resources Development in Institutions of Higher Learning Under the Jurisdiction of Beijing Municipality (Serial Number: PHR201007112) and the program of Academic Human Resources Development in Institutions of Higher Learning Under the Jurisdiction of Beijing Municipality(Serial Number: PHR201007112). The authors thank all the 18 CDC Chronic Disease Departments for their contribution to local investigate and implement.
}

\section{Author details}

'Department of Epidemiology and Health Statistics, School of Public Health and Family Medicine, Capital Medical University, No.10 Xitoutiao, You An Men Wai, Beijing, China. ${ }^{2}$ Xuanwu District Centre for Disease Control and Prevention, No. 34, Changchunjie Xuanwu District, Beijing, China. ${ }^{3}$ Institute of
Chronic and Noncommunicable Disease Control and Prevention, Beijing Center for Disease Prevention and Control, Beijing, China.

\section{Authors' contributions}

$X G$ and $P Z$ designed the studies, PZ participated in all data interpretation, and $Y L$ drafted the manuscript. WW, LZ, HW, WW critically reviewed the manuscript. YL carried out statical analysis. All authors have read and approved the final manuscript.

\section{Competing interests}

The authors declare that they have no competing interests.

Received: 23 June 2010 Accepted: 13 October 2010

Published: 13 October 2010

\section{References}

1. Mohiuddin SM, Pepine CJ, Kelly MT, Buttler SM, Setze CM, Sleep DJ, Stolzenbach JC: Efficacy and safety of ABT-335 (fenofibric acid) in combination with simvastatin in patients with mixed dyslipidemia: a phase 3, randomized, controlled study. American Heart Journal 2009, 157:195-203.

2. Caprnda M, Dukat A, Lietava J, Fodor JG: High prevalences of mixed dyslipidemia in healthy Slovak people. Journal of Clinical Lipidology 2008, 2:541.

3. Sharrett AR, Ballantyne CM, Coady SA, Heiss G, Sorlie PD, Catellier D, Patsch W: Coronary heart disease prediction from lipoprotein cholesterol levels, triglycerides, lipoprotein(a), apolipoproteins A-I and B, and HDL density subfractions: The atherosclerosis risk in communities (ARIC) Study. Circulation 2001, 104:1108-13.

4. Sarwar N, Danesh J, Eiriksdottir G, Sigurdsson G, Wareham N, Bingham S, Boekholdt SM, Khaw KT, Gudnason V: Triglycerides and the risk of coronary heart disease: 10,158 incident cases among 262,525 participants in 29 Western prospective studies. Circulation 2007 115:450-8

5. Abello F, Baracco V, Guardamagna O: Diagnostic and clinical aspects of children affected by primary mixed dyslipidemia. Nutrition, Metabolism \& Cardiovascular Diseases 2008, 18:35.

6. Aziz N, Mehmood MH, Mandukhal SR, Bashir S, Raoof S, Gilani AH: Antihypertensive, antioxidant, antidyslipidemic and endothelial modulating activities of a polyherbal formulation (POL-10). Vascular Pharmacology 2009, 50:57-64.

7. Yusuf S, Hawken S, Ounpuu S, Dans T, Avezum A, Lanas F, McQueen M, Budaj A, Pais P, Varigos J, Lisheng L: Effect of potentially modifiable risk factors associated with myocardial infarction in 52 countries (the INTERHEART study): Casecontrol study. Lancet 2004, 364:937-952.

8. Fruchart JC, Sacks F, Hermans MP, Assmann G, Brown WV, Ceska R, Chapman MJ, Dodson PM, Fioretto P, Ginsberg HN, Kadowaki T, Lablanche JM, Marx N, Plutzky J, Reiner Z, Rosenson RS, Staels B, Stock JK, Sy $R$, Wanner C, Zambon A, Zimmet P: The residual risk reduction Initiative: A call to action to reduce residual vascular risk in patients with mixed dyslipidemia. The American Journal of Cardiology 2008, 102:2-34.

9. Paul MS, LaFontaine T, Thomas TR: Know the risks: Lifestyle management of mixed dyslipidemia. ACSM's Health \& Fitness Journal 2006, 10:18-25.

10. Whittemore R, Melkus G, Wagner J, Dziura J, Northrup V, Grey M: Translating the diabetes prevention program to primary care: A pilot study. Nurs Res 2009, 58:2-12.

11. Libby P: Inflammation in atherosclerosis. Nature 2002, 420:868-74.

12. Gould AL, Rossouw JE, Santanello NC, Heyse JF, Furberg CD: Cholesterol reduction yields clinical benefit: a new look at old data. Circulation 1995, 91:2274-82.

13. Syed MA, Mark EC, John FD: Management of Dyslipidemia in Adults. American family physician 1998, 5:2207.

14. Teramoto T, Sasaki J, Ueshima H, Egusa G, Kinoshita M, Shimamoto K, Daida H, Biro S, Hirobe K, Funahashi T, Yokote K, Yokode M: Goals of dyslipidemia management. Journal of Atheroscler Thromb 2007, 14:2009-12.

15. Perriere $\mathrm{G}$, Thioulouse $\mathrm{J}$ : Use and misuse of correspondence analysis in codon usage studies. Nucleic Acids Research 2002, 30:4548-55.

16. Busold CH, Winter S, Hauser N, Bauer A, Dippon J, Hoheisel JD, Fellenberg K: Integration of go annotations in correspondence analysis: Facilitating the interpretation of micro-array data. Bioinformatics 2005, 21:2424-29. 
17. Neufeld EJ, Mietus-Snyder M, Beiser AS, Baker AL, Newburger JW: Passive cigarette smoking and reduced HDL cholesterol levels in children with high 2 risk lipid profiles. Circulation 1997, 96:1403-7.

18. Rimm EB, Williams P, Fosher K, Criqui M, Stampfer MJ: Moderate alcohol intake and lower risk of coronary heart disease: Meta-analysis of effects on lipids and haemostatic factors. BMJ 1999, 319:1523-8.

19. Stampfer MJ, Krauss RM, Ma J, Blanche PJ, Holl LG, Sacks FM Hennekens CH: A prospective study of triglyceride level, low density lipoprotein particle diameter, and risk of myocardial infarction. JAMA 1996, 276:882-8.

20. Forsythe CE, Phinney SD, Fernandez ML, Quann EE, Wood RJ, Bibus DM Kraemer WJ, Feinman RD, Volek JS: Comparison of low fat and low carbohydrate diets on circulating fatty acid composition and markers of inflammation. Lipids 2008, 43:65-77.

21. Caprnda M, Dukat A, Lietava J, Fodor JG: High prevalences of mixed dyslipidemia in healthy Slovak people. Journal of Clinical Lipidology 2008 2:541

22. Tenkanen $L$, Mänttäri M, Kovanen PT, Virkkunen H, Manninen V: Gemfibrozil in the treatment of mixed dyslipidemia: an 18-year mortality follow-up of the Helsinki Heart Study. Arch Intern Med 2006, 166:743-8.

23. Avins AL, Neuhaus JM: Do triglycerides provide meaningful information about heart disease risk? Arch Int Med 2000, 160:1937-44.

24. Esposito K, Marfella R, Ciotola M, Palo CD, Giugliano F, Giugliano G, D'Armiento M, D'Andrea F, Giugliano D: Effect of a Mediterranean-style diet on endothelial dysfunction and markers of vascular inflammation in the metabolic syndrome. JAMA 2004, 292:1440-6.

25. Stewart KJ, Bacher AC, Turner K, Lim JG, Hees PS, Shapiro EP, Tayback M Ouyang P: Exercise and risk factors associated with metabolic syndrome in older adults. Am J Prev Med 2005, 28:9-18.

doi:10.1186/1476-511X-9-115

Cite this article as: Liu et al:: The characteristics of dyslipidemia patients with different durations in Beijing: a cross-sectional study. Lipids in Health and Disease 2010 9:115.

\section{Submit your next manuscript to BioMed Central and take full advantage of:}

- Convenient online submission

- Thorough peer review

- No space constraints or color figure charges

- Immediate publication on acceptance

- Inclusion in PubMed, CAS, Scopus and Google Scholar

- Research which is freely available for redistribution

Submit your manuscript at www.biomedcentral.com/submit
Biomed Central 